\title{
HACIA UNA REVISIÓN DE LA CARACTERIZACIÓN SEMÁNTICA Y DISCURSIVA DE LA LOCUCIÓN Y ESO QUE EN ESPAÑOL ACTUAL"
}

\section{TOWARDS A REVIEW OF THE SEMANTIC AND DISCURSIVE CHARACTERIZATION OF THE SPANISH IDIOM Y ESO QUE IN CONTEMPORARY SPANISH}

\author{
Araceli López Serena \\ Universidad de Sevilla \\ cheilop@us.es
}

Enviado: 09/01/2018

Aceptado: 08/05/2018

\section{Resumen}

Este trabajo revisa la caracterización semántica, morfosintáctica, discursiva y variacional que las gramáticas y los diccionarios de partículas ofrecen sobre la locución conjuntiva y eso $q u e$. A resultas de ello, se ponen en cuestión algunas de las propiedades que normalmente se le atribuyen a esta construcción, como su supuesta intercambiabilidad con aunque en cualquier contexto, su mayor frecuencia de aparición en

\begin{abstract}
The present paper revises the semantic, morphosyntactic, discursive, and variational characterization that grammars and particle dictionaries offer about the conjunctive locution $y$ eso que. Some of the properties usually attributed to this construction are questioned as a result, such as its alleged interchangeability with aunque in any context, its higher frequency of appearance in an initial intervention
\end{abstract}

\footnotetext{
* Este trabajo forma parte del proyecto de investigación I+D Tradiciones discursivas, tradiciones idiomáticas y unidades de análisis del discurso en la historia del español moderno (FFI2014-51826-P), perteneciente al Plan Estatal 2013-2016 Excelencia del Ministerio de Economía y Competitividad del Gobierno de España, del que soy IP. Su contenido condensa los resultados de tres aproximaciones distintas a la construcción y eso que, que llevé a cabo con motivo de tres reuniones científicas distintas: el workshop "Grammar \& Grammaticalization in interaction: concessive constructions in Spanish and other (Romance) languages", organizado por los Dres. Mar Garachana Camarero y Stefan Pfänder en la Universidad de Friburgo en junio de 2016, el congreso "Enunciado y discurso: estructura y relacionales", celebrado en la Universidad de Sevilla en noviembre de 2016, bajo la dirección de los Dres. Salvador Gutiérrez Ordóñez y Catalina Fuentes Rodríguez, y el congreso "iSin orden ni concierto? La estructura informativa en alemán, español y catalán", que llevó a cabo el Dr. Ferran Robles en la Universidad de Valencia los días 4 a 6 de octubre de 2017. Quisiera agradecer a los organizadores de estos tres coloquios bien su invitación para participar en ellos, bien la aceptación de mis propuestas de comunicación, y a quienes asistieron a alguna(s) de estas tres presentaciones, sus atinadas observaciones, de las que espero haberme hecho eco adecuadamente en estas páginas.
}

Para citar este artículo / To cite this article: López Serena, Araceli (2018). Hacia una revisión de la caracterización semántica y discursiva de la locución y eso que en español actual. ELUA, 32: 195-217. doi: 10.14198/ELUA2018.32.9

Enlace / Link: http://dx.doi.org/10.14198/ELUA2018.32.9 
posición inicial de intervención como recurso óptimo para la toma de turno o su posposición sistemática a la proposición que expresa la consecuencia inesperada y desproporcionada de alguna causa cuyo efecto se preveía mitigar. Los datos que se aducen demuestran asimismo la necesidad de eliminar de su descripción la consideración de que se trata de una estructura impropia de la distancia comunicativa y apuntan, finalmente, a un hecho sobre el que aún no se había dado cuenta en la bibliografía especializada: su reciente conversión, en la lengua periodística, en contextos de inicio de párrafo tras punto y aparte, en un marcador del discurso destinado al cambio de tópico.

PALABRAS CLAVE: $y$ eso que; concesividad; dialogismo; estructuración informativa; variación concepcional; marcadores del discurso. position as an optimal resource for turn taking or its systematic postposition to the clause expressing the unexpected and disproportionate consequence of some cause the effect of which we expected to mitigate. The data adduced equally show the need to remove from its description the assumption that this structure is unbecoming to communicative distance, and finally highlight a fact which still had not been reported in the specialized bibliography: its recent transformation -in journalistic language and within beginning-of-paragraph contexts after a full stop- into a discourse marker used to change topic.

KEY WORDS: y eso que; concessivity; dialogism; information structure; conceptional variation; discourse markers.

\section{INTRODUCCIÓN}

Aunque la información que las gramáticas y los diccionarios de uso o los diccionarios de partículas del español proporcionan sobre la expresión y eso que no es muy abundante, todas las obras de referencia coinciden, generalmente, en resaltar un conjunto muy similar de rasgos ${ }^{1}$. La suma de todos ellos permite confeccionar una caracterización semántica, morfosintáctica, discursiva y variacional de este esquema de construcción, que parece suscitar un considerable consenso y que, al menos por el momento, nadie se ha decidido a poner en cuestión.

Los elementos constantes de las caracterizaciones de y eso que actualmente aceptadas son la consideración de esta estructura como locución conjuntiva con valor concesivo, que rige necesariamente indicativo en el verbo al que antecede, su equivalencia e intercambiabilidad con la conjunción aunque, la manifestación de un perfil concepcional impropio de la máxima distancia comunicativa y afín, por tanto, a la inmediatez u oralidad ${ }^{2}$, su idoneidad como recurso para la toma de turno en las interacciones dialógicas y la convicción de que su surgimiento, en nuestro idioma, como expresión concesiva se produjo a través de un proceso de gramaticalización cuyo antecedente inmediato habrían sido los patrones y eso aunque... / y eso a pesar de que... ${ }^{3}$

1 Cf., p. ej., Seco (1985[1930]), Pérez Rioja (19666), Bosque/Demonte dirs. (1999), Moliner (2000), Cortés Parazuelos (2002), Santos Río (2003), RAE/ASALE (2009).

2 Los términos perfil concepcional, inmediatez y distancia comunicativa se emplean, en estas páginas, en el sentido que se les confiere en la Lingüística de las variedades alemana (cf. Koch/Oesterreicher 1990[2007] y ahora también $2011^{3}$, o López Serena $(2002,2006,2013)$.

3 La refutación de esta hipótesis de gramaticalización, que fue uno de los propósitos de la comunicación presentada en el congreso "Enunciado y discurso: estructura y relacionales", mencionado en la primera nota de este trabajo, no será, sin embargo, objeto de este trabajo. A este respecto, cf. López Serena (2016). 
En consonancia con este estado de cosas, la Nueva gramática de la lengua española (RAE/ASALE 2009) nos proporciona, en los dos epígrafes del capítulo 47 que le dedica, la siguiente información:

Se asimila a las locuciones conjuntivas la fórmula enfática ${ }^{4}$ y eso que, seguida de indicativo y en posición pospuesta. Las oraciones introducidas por y eso que suelen indicar una posible causa que ha sido ineficaz al operar en sentido contrario a lo enunciado en la primera oración ${ }^{5}$ : Se puso furioso, y eso que se lo dije de buen modo; iQué calor, y eso que el verano apenas ha comenzado! El indicativo que sigue a la locución marca el carácter factual del primer miembro. Esta construcción no se suele usar en los registros más formales (NGLE § 47.160).

Las construcciones construidas (sic) con y eso que suelen admitir paráfrasis con prótasis concesivas factuales introducidas por aunque o a pesar de que, pero se diferencian de ellas en que poseen mayor facilidad para aparecer en una construcción independiente en la que se agrega una apostilla a lo que se acaba de decir ( NGLE, § 47.16p).

Esta posibilidad de aparecer en construcciones independientes a modo de apostillas, que parece relacionada con la facilidad para encabezar intervenciones dialógicas de la que ya hablaba la Gramática descriptiva de la lengua española (Bosque/Demonte dirs. 1999) en las escasas 14 líneas de texto que le dedicaba a y eso que (en el epígrafe \$59.3.5.5. del tercer volumen; cf. Flamenco García 1999) es, de hecho, una de las poquísimas informaciones que, a propósito de esta construcción, nos proporcionaba la anterior gramática académica. Sobre ella se resaltaba, por una parte, que se trata de una expresión "muy frecuente en la lengua hablada" y se señalaba, por otra parte, que "pese a la posposición habitual de la prótasis concesiva principiada por y eso que, la anteposición de dicha cláusula también es posible "cuando se trata de una réplica situada al final del diálogo" (sic), como en (1):

4 El carácter enfático que la $N G L E$ atribuye a y eso que está, probablemente, relacionado con el hecho de que María Moliner destaque cómo esta expresión concesiva, que ella también considera "semejante a "aunque»", "acentúa la incongruencia entre las dos oraciones enlazadas. [...] A veces, significa que cierto efecto expresado por la oración principal es muy grande, a pesar de la atenuación que supone lo expresado por la afectada por «y eso que»: "Casi se desmayó, y eso que no le dijimos toda la verdad"” (Moliner 2000, s.v. ese $e^{2}$; la cursiva es mía). La misma postura encontramos en el diccionario de Santos Río, donde leemos, a este respecto, lo siguiente: "Es muy típico su empleo cuando, queriendo el hablante encarecer el hecho narrado por su interlocutor, agrega como comentario la secuencia $Y$ eso que o bien dando a entender que, de no ser por el hecho que se narra, el que acaba de aducir el interlocutor sería todavía más intenso o bien añadiendo un aserto modalizado y enfático, presentado en proposición causa-explicativa condicionada, en el que se explicita ese detalle (-iQué mal papel hizo en la carrera! - Y eso que le ayudaron, que, si no, ni siquiera llega a la meta; podría incluso suspenderse la frase tras el sintagma condicional: Y eso que le ayudaron, que si no...)" (Santos Río 2003, s.v. y eso que; la cursiva es mía).

5 En términos similares define el valor semántico de esta construcción Luis Santos Río: “[i]ntroduce, siempre como apéndice y tras pausa obligada, un hecho que en el contexto se supone obstaculizante en relación con otro que el propio hablante (o su interlocutor) ha descrito en el segmento de discurso inmediatamente anterior" (Santos Río 2003, s.v. y eso que).

6 Algo que, como acabamos de ver, en la NGLE se retoma diciendo que "no se suele usar en los registros más formales", y que está en consonancia con lo ya aducido, mucho antes, por el Diccionario de modismos de Ramón Caballero, que, como señala Cortés Parazuelos (2002: 498), dice de y eso que que es una "expresión familiar que equivale a decir: a pesar, no obstante, sin perjuicio, etc." (Caballero 1942, s.v. y eso que). 
(1) A: Este marisco está riquísimo.

B: Pues ya ves, $\ldots$ y eso que esta mañana no había mucho donde elegir en el mercado (GDLE, § 59.3.5.5., pág. 3835)7.

Si tomamos como punto de partida los dos extractos, reproducidos más arriba, de la última gramática académica, y sumamos a su contenido lo ya estipulado, previamente, a propósito de y eso que, por Moliner (2000), Santos Río (2003) o la GDLE (Flamenco García 1999), identificaremos con facilidad un elenco conformado por un total de nueve rasgos, dos de ellos morfosintácticos, cuatro semánticos y tres discursivos, que reproduzco, de forma más sistemática, en la figura 1 a continuación:

Caracterización morfosintáctica:

(a) NATURALEZA: Se asimila a las locuciones conjuntivas.

(b) RECCIÓN: Va seguida de indicativo.

Caracterización semántica:

(c) Fórmula enfática.

(d) Y ESO QUE: Debido a su contenido, admite paráfrasis con prótasis concesivas factuales introducidas por aunque o a pesar de que.

(e) PROPOSICIÓN INTRODUCIDA POR y eso que:

i. (en construcción dependiente): causa que ha sido ineficaz al operar en sentido contrario a lo enunciado en la primera oración.

ii. (en construcción independiente): apostilla a lo que se acaba de decir.

(f) MODO VERBAL DE LA PROPOSICIÓN INTRODUCIDA POR y eso que: el indicativo que sigue a la locución marca el carácter factual del primer miembro.

Caracterización discursiva:

(g) Posición pospuesta.

(h) Facilidad para aparecer en una construcción independiente.

(i) No se suele usar en los registros más formales.

Figura 1. Rasgos morfosintáticos, semánticos y discursivos

de y eso que según la NGLE

7 Qué entiende la GDLE por anteposición (cuando en el ejemplo que nos da la secuencia encabezada por y eso que ni está en inicio de intervención, ni va seguida de absolutamente nada a lo que se pueda estar anteponiendo (y desde luego a nada que actúe como el argumento con respecto al que el contenido de la cláusula encabezada por y eso que desempeñe la función de impedimento no efectivo o de causa ineficaz, es un misterio). Como también qué pueda entender esa misma obra por diálogo y por posición final de diálogo. Por ahora, baste dejar constancia de la estupefacción que cualquier analista del discurso siente a la vista de la descripción del ejemplo reproducido en (1). Más adelante (ejs. 23 a 26) se aducirán unos pocos ejemplos (realmente muy escasos en el corpus manejado) donde sí hay auténtica anteposición, y ello no necesariamente vinculado a la aparición de $y$ eso que en posición inicial de un turno ubicado en una intervención reactiva, es decir, en el segundo miembro de un intercambio dialógico (los términos diálogo, intercambio, intervención, intervención reactiva y turno se emplean, en este trabajo, en el sentido en que se definen en Briz y Grupo Val.Es.Co. 2003, 2014). Cf., a este respecto, la fig. 3 infra. 
En principio, todos estos rasgos se antojan absolutamente aceptables y la imagen sobre $y$ eso que que se desprende de su combinación es, al menos en apariencia, totalmente convincente. Y, sin embargo, lo cierto es que muchos de estos rasgos no logran superar con éxito su contrastación con datos de corpus. Más bien al contrario, la conclusión a la que aboca el análisis pormenorizado de los algo más de cinco centenares de ejemplos que proporcionan las bases de datos de la propia Academia es la de la necesidad bien de desestimar, bien de precisar, al menos en parte, los términos en que se formulan la caracterización semántica y la caracterización discursiva de la construcción. A tal fin, se han tenido en cuenta todas las ocurrencias que de la forma y eso que arrojan los corpus CREA y CORDE, cuya consideración obliga a revisar los rasgos semánticos (d) " $y$ eso que admite paráfrasis con prótasis concesivas factuales introducidas por aunque o a pesar de que" y (e ii.) "en construcción independiente, la proposición introducida por y eso que contiene una apostilla a lo que se acaba de decir", así como la totalidad de la caracterización discursivo-variacional que se aceptaba como válida hasta la fecha, conformada por las tres propiedades que se enumeran en la última celda de la figura 1: (g) "ocupa sistemáticamente la posición pospuesta", (h) "tiene facilidad para aparecer en una construcción independiente", (i) "no se suele usar en los registros más formales".

\section{CARACTERIZACIÓN SEMÁNTICA Y PERFIL CONCEPCIONAL DE Y ESO QUE}

\subsection{Concesividad, argumentación y dialogismo}

En la caracterización semántica de las construcciones concesivas con y eso que, el significado que se asume como prototípico de la proposición introducida por y eso que, cuando la construcción no es independiente, es, bien, como afirma la Academia, el de "causa que ha sido ineficaz al operar en sentido contrario a lo enunciado en la primera oración" (NGLE $\S 47.160$; cf. supra), bien, como expone Santos Río (2003, s.v. y eso que), el de "hecho que en el contexto se supone obstaculizante en relación con otro que el propio hablante (o su interlocutor) ha descrito en el segmento de discurso inmediatamente anterior" (cf. supra, n. 5). Si nos referimos a la proposición que expresa la causa ineficaz o el hecho que debería haber actuado como obstaculizante como Q y a la que manifiesta la consecuencia no evitada o el efecto que se preveía inesperado como $\mathrm{P}$, y representamos el significado de la relación que, a través de y eso que, se establece entre ambas proposiciones en forma de esquema, obtendríamos algo parecido a la figura 2, en la que se incluye también la causa, habitualmente elíptica, de ese efecto que supuestamente lo enunciado por Q habría debido impedir o, al menos, mitigar:

\begin{tabular}{|l|l|l|l|}
\hline (causa elíptica) $=>$ & $\begin{array}{l}\text { efecto inesperado (y } \\
\text { desproporcionado) }\end{array}$ & y eso que & $\begin{array}{l}\text { circunstancia supuestamente } \\
\text { atenuadora del efecto }\end{array}$ \\
\hline & Se puso furioso & yeso que & se lo dije de buen modo \\
\hline
\end{tabular}

Figura 2. Esquema semántico de la construcción $\mathrm{P}$ y eso que $\mathrm{Q}$ 
El carácter bimembre de este esquema semántico, entre cuyas proposiciones constituyentes se establece una relación de contraste, está en consonancia con la manera en que la inmensa mayoría de los estudios sobre concesividad coincide en resaltar el hecho, aparentemente incontestable, de que "las estructuras gramaticales concesivas responden a necesidades de [...] comunicación" relacionadas con la "negociación entre posiciones o entre opiniones" (Pérez Saldanya 2014: 3699), propias de necesidades de comunicación generadas en situaciones como "el debate manifiesto o latente, la argumentación persuasiva, la búsqueda del consenso entre posturas discrepantes o la presentación del enunciador como persona transigente" (Pérez Saldanya 2014: 3699), así como a la convicción de que "[e]llo supone la consideración de un dialogismo subyacente que, en una situación primaria, correspondería a la interacción conversacional y, prototípicamente, a situaciones de debate o al menos de divergencia entre los puntos de vista de los interlocutores" (Pérez Saldanya 2014: 3702).

Por otro lado, en relación con el perfil concepcional de la construcción, como ya se ha señalado más arriba, esta se ha considerado, tradicionalmente, "expresión familiar" (cf. supra, n. 6) y, más recientemente, tanto "muy frecuente en la lengua hablada" (GDLE, $\S 59.3 .5 .5)$ como "inusual en los registros más formales" (NGLE § 47.16o). Además, la presencia de la copulativa $y$ como elemento inicial de la estructura parece constituir un procedimiento apto para la toma de turno en intercambios dialogales propicios para la co-construcción discursiva. Esto, unido a la polifonía o dialogismo asociados al valor semántico de concesividad, me llevó a pensar que, si tras el análisis de corpus se confirmaba su presencia predominante en dichos contextos - como el que recrea Juan Rulfo en el fragmento de El llano en llamas que se reproduce como ejemplo (2) a continuación-, esto apuntaría a la posibilidad de que su gramaticalización se hubiera originado en contextos netamente interaccionales ${ }^{8}$.

(2) - ...Oye, Melitón, ¿como cuánto dinero nos costó darles de comer a los acompañantes del gobernador?

- Algo así como cuatro mil pesos.

- Y eso que nomás estuvieron un día y en cuanto se les hizo de noche se fueron (Llano, 143, ápud Pérez Saldanya 2014: 3815; la cursiva es mía).

En efecto, a mi modo de ver, y eso que parecía compartir con otras estructuras concesivas del español formalmente tripartitas, encabezadas, también, por la conjunción copulativa $y$, con una expresión nuclear que podríamos considerar apelativo-ponderativa, y culminadas por una conjunción completiva $-y$ o que- (véanse los ejemplos de (3), infra, que tomo de Cortés Parazuelos 2002), cuyos procesos de gramaticalización aún no están suficientemente estudiados, un perfil concepcional que la mayoría de los hablantes del español calificaríamos, indudablemente, de prototípicamente coloquial:

(3) Se le ha llevado el coche la grúa. Y mira que se lo he dicho veces.

Se le ha llevado el coche la grúa. $Y$ vaya si se lo he dicho veces.

Se le ha llevado el coche la grúa. Y cuidado que se lo he dicho veces.

8 Precisamente los que nos habían interesado en el workshop que tuvo lugar en Friburgo, al que se alude en la primera nota al pie de este trabajo. 
Por este motivo, creí acertado dar por descontado que nos toparíamos con ella en corpus de conversaciones coloquiales como el del Grupo Val.Es.Co. -donde aparece, es verdad, pero lo cierto es que con muy poca frecuencia, tanto en secuencias monológicas de posible interpretación concesiva (4), como en secuencias estructuralmente dialógicas (5):

(4) $[\ldots]$ y le dio el porrazo $\uparrow$ y ella se asustóo $\uparrow / y$ el coche p'atrás p'atrás p'atrás y se fue p'atrás/ y eso que nosotrah no habíamoh bajao [...] (Briz y Grupo Val.Es.Co. 2002: 256).

(5) Eduardo: Pitu va- se va a cenar con la familia de su novio / es que la familia de su novio celebra mucho la Navidad y todo eso.

Elena: y eso que son ateos / (RISA) (Cabedo y Pons, eds., Corpus Val.Es.Co. 2.0. [en línea]; conversación 0038, líneas 191-192)-,

y asumí, como hipótesis de partida la atribución, a la estructura con y eso que, de un perfil concepcional coloquial y su aparición prevalente en pares adyacentes en los que y eso que encabeza la intervención reactiva. Esta posición era, desde luego, la preferida por la mayoría de los autores consultados. De hecho, como hemos visto, además de Pérez Saldanya, también Flamenco García (1999) propone un ejemplo de este tipo para mostrar el funcionamiento de esta estructura9 ${ }^{9}$ Y lo mismo hace Luis Santos Río (2003), quien ilustra su definición de y eso que con los siguientes intercambios dialógicos:

(6) - Qué bien juega.

-Y eso que está lesionado (Santos Río 2003, s.v. y eso que).

(7) -iQué mal papel hizo en la carrera!

-Y eso que le ayudaron, que, si no, ni siquiera llega a la meta (Santos Río 2003, s.v. y eso que).

Frente a ellos, es interesante que María Moliner se decante, exclusivamente, por ejemplos monológicos:

(8) Ha llegado tarde, y eso que no tenía nada que hacer (Moliner 2000, s.v. ese ${ }^{2}$ ).

(9) Casi se desmayó, y eso que no le dijimos toda la verdad (Moliner 2000, s.v. ese ${ }^{2}$ ).

\subsubsection{Y eso que en inicio de intervención y/o turno}

Mis indagaciones en torno a la naturaleza polifónica y oral de y eso que y a su supuesta prevalencia en estructuras de toma de turno en el segundo miembro de un par adyacente, que ya se habían encontrado con dificultades en corpus conversacionales como el de Val.Es.Co., se vieron asimismo frustradas cuando acudí a otras fuentes de ejemplos. En efecto, tampoco los datos que arrojaban los corpus CREA y CORDE de la Real Academia Española avalaban la hipótesis del origen dialógico o interaccional de la construcción. En primer lugar, por la escasez de ejemplos en que y eso que se manifiesta en posición inicial de intervención: en efecto, de las 597 ocurrencias de y eso que

9 Como se advierte al final de los propios ejemplos, el de Juan Rulfo, reproducido en (2), está tomado de Pérez Saldanya, mientras que el (1) procede de Flamenco García (1999). 
registradas en el CREA -a las que debemos restar los 39 casos en los que la estructura aparece en usos no gramaticalizados $y$, por tanto, no concesivos ${ }^{10}$, lo que nos deja un total de 558 ocurrencias de y eso que concesivo-, solamente 59 son de usos de esta estructura en posición inicial de turno en la segunda intervención de un par adyacente (véase infra la tabla número 4). A esto se suma el problema de que la mayoría de estos ejemplos son, o bien literarios, como el ya visto de Rulfo en (2), o bien periodísticos. Dentro de este último tipo abundan, fundamentalmente, los ejemplos procedentes de entrevistas escritas (10) y los que se manifiestan en forma de declaraciones entrecomilladas insertas en mitad del discurso del periodista (11).

(10) - [...] Hasta una pequeña anécdota, como es el preservativo, acabó convirtiéndose en una necesidad de supervivencia que condiciona el comportamiento libre de la sexualidad humana, por ejemplo. El sida mató al cáncer, enfermedad de la que ya no se habla.

- Y eso que sigue actuando, desgraciadamente. (El Mundo, 19/02/1994, "Lisboa, capital cultural”. Entrevista con el escritor Jose Cardoso Pires, ápud CREA; la cursiva es mía).

(11) Don Juan Carlos mostró su alegría por el resultado favorable al Madrid y comentó: " $Y$ eso que Maradona decía que iba a ir dando patadas" (El País, 01/10/1987, "El Rey dio el resultado a los periodistas", ápud CREA; la cursiva es mía).

De hecho, lo más frecuente en los ejemplos dialógicos del CREA, como ocurre en los que se ofrecen entre (12) y (14) infra, es que y eso que aparezca no en posición inicial de intervención, sino en mitad del desarrollo de esta; es decir, en contextos que, de acuerdo con la propuesta de unidades para la segmentación de la conversación realizada por el grupo Val.Es.Co., computan, en términos estructurales, como ejemplos monológicos, y no como mecanismos de interacción (cf. fig. 3):

\begin{tabular}{|c|c|c|c|}
\hline NIVEL & & DIMENSIONES & \\
\hline Dialógico & $\begin{array}{c}\text { ESTRUCTURAL } \\
\text { discurso } \\
\text { diálogo } \\
\text { intercambio }\end{array}$ & $\begin{array}{l}\text { SOCIAL } \\
\text { alternancia de turnos }\end{array}$ & INFORMATIVA \\
\hline MonOlÓGICO & $\begin{array}{l}\text { intervención } \\
\text { acto }\end{array}$ & turno & subacto \\
\hline
\end{tabular}

Figura 3. Niveles, dimensiones de análisis y unidades e análisis del discurso según Val.Es.Co. (2014)

10 Usos frecuentes, sobre todo en las muestras que CREA cataloga como orales informales, como la siguiente: "Dice: «Madre, qué majo". Y llevaba unas pichorritas aquí colgando. Y le dijimos: «¿Y eso que parece una de comer?». Y dice: «Esto es la bomba de mano»". (CREA, España, ORAL, No te rías que es peor, Madrid, 19/12/91, TVE 1; la cursiva es mía). 
Este tipo de ejemplos, procedentes tanto del CREA oral como de prensa escrita o literatura, a los que pertenecen, respectivamente, los casos de (12), (13) y (14) infra, asciende, en CREA, a un total de 195 ocurrencias, una cantidad muy superior a los 59 ejemplos de $y$ eso que concesivo en inicio de turno a los que me había referido más arriba.

(12) Las primogénitas siempre hemos sido mujeres, y siempre nos hemos llamado Rocío. Que ya no es Rociito, será Rociiiito. Dicho así. Han oído hablar de ellas, ¿verdad? Y eso que hace menos de veinte días que han nacido todas. (Qué me dices, Tele 5, 19/10/96, ápud CREA).

(13) - [...] Después de 20 tomas, Wolfgang Petersen, el director, me llamó aparte y me dijo que el primer día de trabajo con Clint Eastwood en "En la línea de fuego", (sic) necesitó 40 tomas para que dijera su parte con soltura... Y eso que Clint tiene fama de ser rápido... (La Vanguardia, 03/04/1995, Gabriel Lerman, ápud CREA).

(14) - Hay también el problema de las chicas -insinuó mi padre-, las chicas del conjunto. Nosotros en nuestra compañía no traemos.

- ¿Cómo que no? Traen ustedes dos mozas que valen la pena, creo yo. Como ésas en el pueblo no las hay. Y eso que las sacan ustedes de trapillo. Que ya las quisiera yo ver con poca ropa, y lentejuelas y plumas. (Fernando Fernán Gómez, El viaje a ninguna parte, España, 1985, ápud CREA).

\subsubsection{Y eso que en posición estructuralmente monológica}

Al hecho de que la estructura no abunde en contextos de interacción propiamente dicha, como elemento de apertura de intervención en un esquema de alternancia de turnos, se suma, en segundo lugar, el problema de la comparecencia masiva de este patrón de construcción en secuencias estructuralmente monológicas, tanto en el marco de una conversación como en el de un texto expositivo, narrativo, etc. Este uso monológico de y eso que no se restringe únicamente a los registros informales. Más bien al contrario, su comparecencia en textos escritos moderadamente distantes conforma la aplastante mayoría de ocurrencias detectadas en el corpus. En el caso del CREA, estamos hablando de alrededor de unos 385 ejemplos, hallados mayoritariamente en fuentes periodísticas (casi dos centenares de ejemplos: 178), literarias (en torno a un centenar: 99) y en libros ensayísticos o de divulgación de temática variada, de los que ofrezco una reducida selección: el ejemplo número (15), de una crónica taurina, el (16), de contenido político, el (17), extraído de un libro de Geología, el (18), de otro de Antropología y mi favorito, el número (19), que tomo de la monografía sobre Poesía juglaresca y juglares de don Ramón Menéndez Pidal.

(15) El presidente es como un padre. Para la empresa y para los toreros es como un padre el presidente. En cambio, para la afición, madrastra. Y eso que la afición se pasa de buena. (El Pais, 02/10/1989, CREA; la cursiva es mía).

(16) La batalla interna en el PP (Camps - Zaplana) está resultando sangrienta. Las declaraciones ayer del secretario general, José Joaquín Ripoll, contra el Consell y la CAM, 
salvando a Bancaja, que preside José Luis Olivas, son el más claro bando de guerra. $Y$ eso que el 28 de abril firmaron la paz. (El Periódico Mediterráneo, 21/05/2004; CREA).

(17) Sorprende comprobar cómo en naciones como la nuestra, de civilizaciones muy antiguas, buena parte de los distritos mineros que se vienen explotando en nuestros días, (sic) eran ya conocidos desde hace milenios, habiendo sido beneficiados por sus primeros pobladores. Y eso que no siempre los minerales metálicos eran fácilmente detectables de modo directo, sino que había que saber buscarlos, averiguando las relaciones que los ligan a distintos tipos de rocas e indicios geológicos (Adriano García-Loygorri, Apuntes históricos sobre los comienzos del aprovechamiento del carbón..., 1990, CREA).

(18) Concluyeron que el 98,4 por ciento de los genes de un hombre están presentes en el chimpancé, lo que reducía la diferencia a algo menos de 50 genes. Y eso que entonces partían de la hipótesis de que un humano dispone de 100.000 genes (Bruno Cardeñosa, El código secreto. Los misterios de la evolución humana, 2001, CREA).

(19) No nos consta que Bonaval alcanzase el reinado de Alfonso X; su nombre no se halla entre los que satirizaron a la Balteira, y eso que ésta comenzó su carrera en días de san Fernando, si bien no logró su fama escandalosa hasta por los años 1258-1266 (Menéndez Pidal, Poesía juglaresca y juglares. Orígenes de las literaturas románicas, 1924-1957, CORDE).

\subsection{Y eso que, una construcción sin perfil concepcional prototípico}

Cuando se utilizan los datos procedentes de los bancos de muestras académicos, conviene ser consciente del peligroso sesgo que afecta al CREA, que tiene una abrumadora mayoría de datos procedentes de libros impresos y prensa periódica (cf. las tablas 1 y 2, de acuerdo con las cuales, de los 154.212.661 palabras que conforman el CREA, 151.379.903 (esto es, un 98,16\%) proceden de fuentes escritas, libros y prensa, por lo que entendemos que solamente la diferencia entre ambas cantidades, 2.832 .758 (un 1,94\% de los datos), debe ser de naturaleza oral:

\begin{tabular}{lc}
\hline Corpus & Palabras \\
\hline CORDE & 236709914 \\
CREA & 154212661 \\
\hline
\end{tabular}

Tabla 1. Número total de palabras contenidas en los corpus CORDE y CREA

\begin{tabular}{cccc}
\hline Medio & Palabras CORDE & Palabras CREA & Total palabras \\
\hline Libros & 234056904 & 80677065 & 314733969 \\
Prensa & 2653010 & 70702838 & 73355848 \\
Miscelánea (solo CREA) & & 2832758 & 2832758 \\
\hline
\end{tabular}

Tabla 2. Número de palabras procedentes de prensa y libros del total de palabras contenidas en los corpus CORDE y CREA 
Por esta razón recurrí al análisis cualitativo de los datos, en busca de ejemplos de oralidad mimética en libros de ficción, así como de ocurrencias de y eso que integradas en fragmentos que el CREA etiqueta como periodísticos o librescos pero que proceden de intervenciones originariamente orales (en sentido tanto medial como concepcional ${ }^{11}$ ). Para afinar la caracterización de los ejemplos, en relación con la naturaleza medial originaria de las ocurrencias, tuve en cuenta si se trataba de datos procedentes de transcripciones orales incluidas en CREA oral o de datos extraídos de documentos escritos. Tanto en un caso como en otro, diferencié los ejemplos hallados en secuencias monológicas de aquellos que aparecían en estructuras dialógicas, $\mathrm{y}$, a su vez, los atestiguados en inicio de intervención de aquellos que se daban en posición intermedia de intervención. Para los ejemplos provenientes de documentos escritos detectados en secuencias monológicas, se atendió a tres variables posicionales: (i) aparición tras declaraciones entrecomilladas, (ii) aparición en inicio de párrafo o (iii) aparición en posición intermedia de párrafo. De esta manera, fue posible computar como ejemplos de naturaleza dialógica tanto aquellos en posición inicial de turno que se extrajeron de transcripciones orales (59 casos) y de textos estructuralmente dialogales (entrevistas escritas) (202 casos), como los ejemplos provenientes de transcripciones orales hallados en mitad de intervención (19 casos), y también los procedentes de documentos escritos que manifestaran algún tipo de polifonía, por ejemplo, porque el periodista-locutor dialogara con otras voces o enunciadores presentes en su texto, como ocurre en los 20 casos en que el periodista-locutor prosigue su propio discurso mediante un enunciado encabezado por y eso que con que replica a las palabras entrecomilladas de alguna fuente.

Con todo, los resultados de este tipo de análisis variacional cualitativo tampoco permiten inclinar la balanza a favor del carácter oral y dialógico de la construcción. Gracias a la consideración conjunta de ejemplos concepcional y medialmente orales y de ejemplos medialmente escritos pero de perfil concepcional oral, el cómputo manual y el análisis cualitativo (cuyos resultados se ofrecen en la tabla número 4 infra) hacen posible aumentar el número de ejemplos de perfil concepcional oral a 288 (frente a los 114 que arroja la tabla 3 infra, que contempla únicamente el etiquetado de la Academia). Pero, aun así, no podemos concluir que y eso que sea una estructura prototípicamente oral y poco frecuente fuera de la inmediatez comunicativa.

\begin{tabular}{|l|l|l|l|}
\hline Número de ejemplos "orales" & 114 \\
\hline Número de ejemplos “escritos" & Libros & \multicolumn{3}{|l|}{} \\
\cline { 2 - 3 } & Periódicos & 159 \\
\cline { 2 - 3 } & Revistas & 34 \\
\cline { 2 - 3 } & Miscelánea & 9 & \multirow{3}{*}{492} \\
\hline Número total de ejemplos & & 606 \\
\hline
\end{tabular}

Tabla 3. Distribución de los ejemplos de CREA, según las categorías de la propia base de datos

11 En sentido medial, se contemplan ejemplos de extracción fónica y, en sentido concepcional, ejemplos procedentes de los registros informales que se ven propiciados por situaciones de inmediatez comunicativa. Los conceptos proceden, una vez más, de Koch/Oesterreicher (1990[2007], 2011³). 


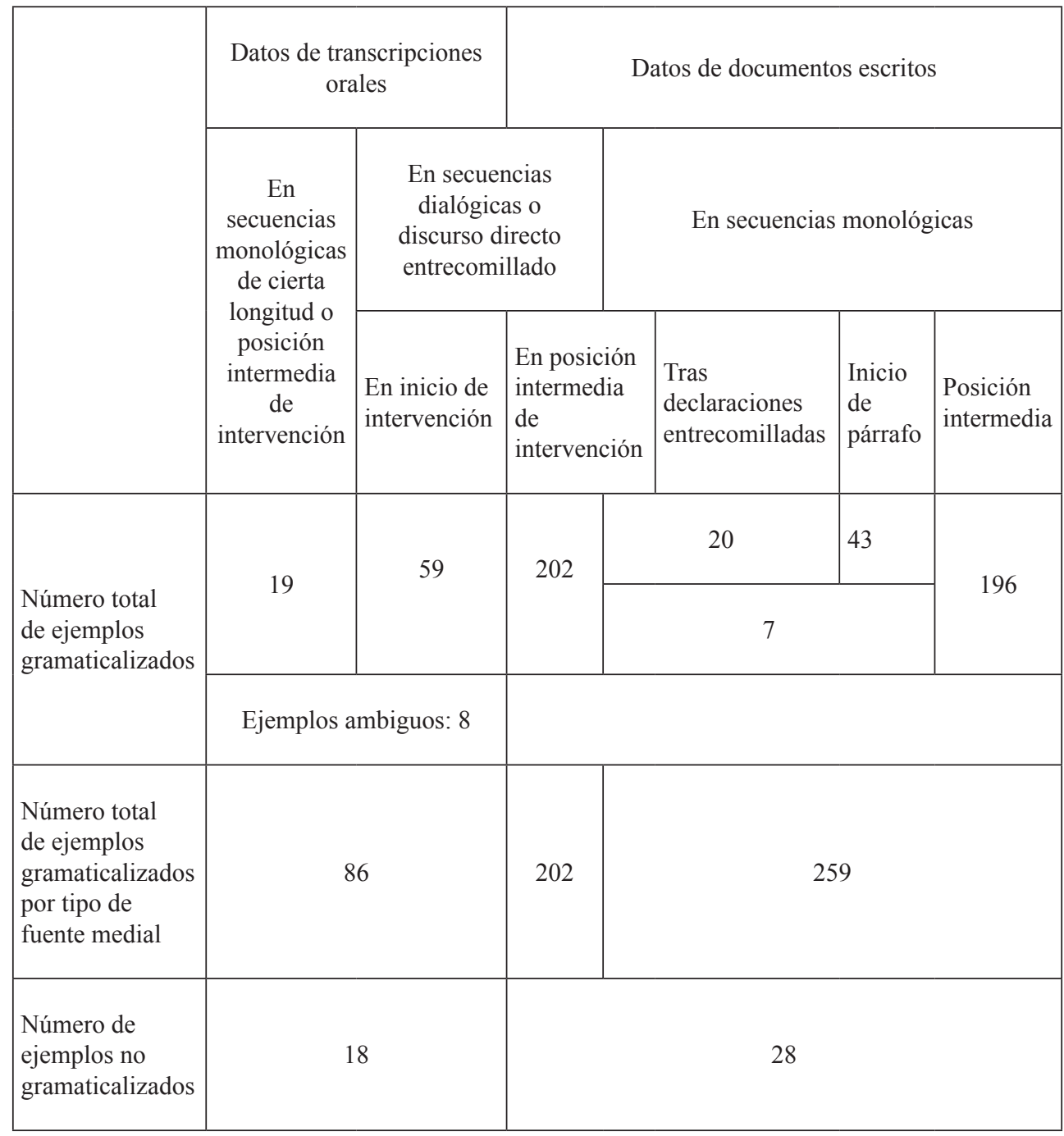

Tabla 4. Distribución de los ejemplos de CREA, según el perfil concepcional y carácter monológico o dialógico de las muestras

De hecho, más bien al contrario, a la luz de estos datos, es inevitable concluir que $y$ eso que es una estructura muy abundante en fuentes escritas, y no solo en pasajes donde se pueda considerar un efecto estilístico perseguido de mímesis de la oralidad, sino también en textos periodísticos o en prosa técnica y científica (y no solo de divulgación). Así las cosas, el último de los rasgos discursivos de esta construcción contemplados por la NGLE que recogimos en la fig. 1, el rasgo (i) "no se suele usar en los registros más formales", que volvemos a reproducir a continuación, con esta característica tachada de la lista de rasgos discursivos, debería eliminarse de su descripción: 
Caracterización morfosintáctica:

(a) NATURALEZA: Se asimila a las locuciones conjuntivas.

(b) RECCIÓN: Va seguida de indicativo.

Caracterización semántica:

(c) Fórmula enfática.

(d) Y ESO QUE: Debido a su contenido, admite paráfrasis con prótasis concesivas factuales introducidas por aunque o a pesar de que.

(e) PROPOSICIÓN INTRODUCIDA POR y eso que:

i. (en construcción dependiente): causa que ha sido ineficaz al operar en sentido contrario a lo enunciado en la primera oración.

ii. (en construcción independiente): apostilla a lo que se acaba de decir.

(f) MODO VERBAL DE LA PROPOSICIÓN INTRODUCIDA POR y eso que: el indicativo que sigue a la locución marca el carácter factual del primer miembro.

Caracterización discursiva:

(g) Posición pospuesta.

(h) Facilidad para aparecer en una construcción independiente.

(i) No se strele trar en los registros más formales.

Figura 1'. Rasgos morfosintáticos, semánticos y discursivos de y eso que según la NGLE

Por último, la imposibilidad de asociar las construcciones con y eso que a la esfera de la interacción y de la oralidad se ve reforzada cuando se consideran los datos que ofrece el CORDE. En esta otra base de datos académica, de nuevo, los primeros ejemplos de $y$ eso que con valor concesivo que se documentan, de mediados del s. XVIII, son, como la mayoría de los casos que hemos visto que también arroja el CREA, estructuralmente monológicos:

(20) El reverendo autor de las crónicas seráficas de su provincia de san Gregorio, dice que en las islas de Calamaines y Paragua, hay puercoespines; pero en éstas no se hallan, ni tengo noticia que existan en la de Manila y Mindanao, y eso que son de grande extensión las dos. (Juan José Delgado, Historia general sacro-profana, política y natural de las islas del Poniente llamadas Filipinas, c. 1754, CORDE).

(21) ¡Escucha, escucha, Paquilla!

Yo voy á ver si la alcanzo,

no me arme algún caramillo

con Teresa. Ya estoy harto

de enredos y de mujeres,

y eso que aún no me he casado. (Ramón de la Cruz, El novio rifado, 1762, CORDE).

\section{LA POSICIÓN DE LA PROPOSICIÓN INTRODUCIDA POR Y ESO QUE}

Tal como quedó reflejado en la figura 1 supra, y de acuerdo con las caracterizaciones efectuadas hasta la fecha, las construcciones concesivas con y eso que ocupan, sistemáticamente, la posición pospuesta (cf. $N G L E \S 47.160 ;$ ). Absolutamente explícito en este sentido 
es Santos Río (2003), quien afirma que y eso que "[i]ntroduce, siempre como apéndice y tras pausa obligada, un hecho que en el contexto se supone obstaculizante en relación con otro que el propio hablante (o su interlocutor) ${ }^{12}$ ha descrito en el segmento de discurso inmediatamente anterior" (Santos Río 2003, s.v. y eso que; la cursiva es mía).

Pues bien, aunque en los centenares de ejemplos analizados para este trabajo la posposición de la proposición encabezada por y eso que es, en efecto, absolutamente mayoritaria, entiendo que las descripciones gramaticales y discursivas de este esquema de construcción deberían contemplar, al menos como posibilidad -y tendrían, consecuentemente, que explicar-, casos de anteposición como el siguiente:

(22) MARISA: Y eso que solo se tomó la mitad de la copa, hay que ver el efecto tan rápido que le ha hecho. (Juan José Alonso Millán, El guardapolvo, 1990, CREA).

También hay anteposición en estos otros cuatro ejemplos del CORDE, en el segundo y el tercero de los cuales ( 24 y 25 , respectivamente) la cláusula de y eso que ocupa una posición parentética dentro de la proposición u oración, aún no finalizada, a la que esperaríamos que se pospusiera completamente, mientras que el cuarto (el número 26) pertenece, decididamente, al grupo de concesivas que Garachana (1999) denomina metalingüísticas:

(23) Fue la primera vez, entre tantas visitas, y eso que la despedida era por algún tiempo, que salió a la calle sin recriminarse a sí mismo por su falta de resolución, satisfecho con la idea de que la viuda acababa de confesarle verdaderamente su amor, y que le bastaba venirse cualquier día de Asunción para hacerla suya (Gabriel Casaccia, La Babosa [Paraguay], 1952, CORDE).

(24) $[\ldots]$ los derechos de hoy -y eso que son tradicionales, que son antiguos- son generalmente mezquinos, son más modestos, son pocos (Nicomedes Pastor Díaz, Discurso contestando al señor Rodríguez Camaleón sobre su proposición para que dejase el clero..., 1863, CORDE).

(25) - ¡Todo sea por Dios! -exclamó el prelado con abatimiento-. - ¡Ah! No sabes, Gudesindo, y eso que nadie tiene obligación de saberlo más que tú, no sabes cuántos enemigos tengo en la ciudad, en esta misma casa (Francisco Navarro Villoslada, Doña Urraca de Castilla, 1849, CORDE).

(26) Miguel se puso colorado y el consabido sudorcillo de las situaciones apuradas comenzó a inundarle el cogote. Él había traducido francés, en otra época, había leído el Telémaco y algo del Gil Blas... Pero temía que la lengua del vecino imperio, como él llamaba a Francia, y eso que hacía algunos años de la caída de Napoleón, temía que la lengua del vecino imperio se le hubiese ido de la memoria (Clarín, Pipá, 1886, CORDE).

12 Obsérvese cómo se destaca el carácter dialógico, propicio para la co-construcción del período concesivo, del esquema con y eso que, al que nos hemos referido en el epígrafe anterior y sobre el que este mismo autor vuelve a insistir más adelante, con las siguientes palabras: "va siempre precedido de pausa (coma o punto [A, y eso que B. A. Y eso que B] si el hecho obstaculizado lo narra el mismo hablante y necesariamente un punto si, usada como encabezador de un segmento reactivo, introduce cambio de turno conversacional" (Santos Río 2003, s.v. y eso que). 
A la luz de estos hechos, habría que rehacer, de nuevo, la figura 1, que, tras la corrección relativa al rasgo (g), que se destaca en cursiva, quedaría, de momento, como sigue:

Caracterización morfosintáctica:

(a) NATURALEZA: Se asimila a las locuciones conjuntivas.

(b) RECCIÓN: Va seguida de indicativo.

Caracterización semántica:

(c) Fórmula enfática.

(d) Y ESO QUE: Debido a su contenido, admite paráfrasis con prótasis concesivas factuales introducidas por aunque o a pesar de que.

(e) PROPOSICIÓN INTRODUCIDA POR y eso que:

iii. (en construcción dependiente): causa que ha sido ineficaz al operar en sentido contrario a lo enunciado en la primera oración.

iv. (en construcción independiente): apostilla a lo que se acaba de decir.

(f) MODO VERBAL DE LA PROPOSICIÓN INTRODUCIDA POR y eso que: el indicativo que sigue a la locución marca el carácter factual del primer miembro.

Caracterización discursiva:

(g) Posición mayoritariamente pospuesta, con posibilidad tanto de anteposición como de interposición.

(h) Facilidad para aparecer en una construcción independiente.

(i) No se surele usaren los registros más formales.

Figura 1". Rasgos morfosintáticos, semánticos y discursivos de y eso que según la $N G L E$

\section{Y ESO QUE COMO ORDENADOR DEL DISCURSO}

Junto a las propiedades discursivas de las construcciones concesivas con y eso que que, como hemos puesto de relieve hasta aquí, se impone revisar, hay también tres propiedades semánticas de esta estructura que parecen haberse formulado al margen de un tipo de ocurrencias cada vez más frecuentes en la lengua actual, fundamentalmente en los textos periodísticos. En este tipo de textos el esquema y eso que + verbo en indicativo parece haber experimentado una conversión, muy reciente, en un marcador discursivo de ordenación del discurso que introduce, en enunciado independiente y a principio de un nuevo párrafo, un contenido que reúne dos características destacables: la primera es que este contenido se presume consabido por el receptor, y la segunda es que su información se focaliza. Esto es lo que ocurre en ejemplos como 27, 28, 29 y 30, de los que, si volvemos a la tabla 4, comprobaremos que CREA ofrece 43 casos:

(27) El equipo de José Manuel Seco había sumado los seis últimos puntos de la primera vuelta, tras derrotar al Hernani en casa y el UPV fuera, pero no pudo enlazar su tercer éxito consecutivo en el inicio de la segunda.

$Y$ eso que no tardó en encarrilar el partido con un tanto madrugador de Txtxu, que aprovechó el penalti cometido sobre Txelis (El Diario Vasco, 11/01/2011, CREA). 
(28) Jorge Valdano se atribuyó en exclusiva el error. "Quité a Dubovsky para evitar males mayores. Fue una decisión mía. El error es atribuible a la ansiedad atacante y a la novedad de la presencia de Redondo. Yo cuento en términos futbolísticos y no me fijé en las trabas burocráticas. El incidente tampoco ha sido determinante en el empate. Fue una anécdota, aunque grave".

$Y$ eso que todo había comenzado de cara para los de casa [...] (La Vanguardia, 24/10/1994, CREA).

(29) Hermann Mejía ha tenido la fortuna de unir dos cosas: talento y suerte. Una sola de ellas, como se sabe, no garantiza el éxito. Pero él cuenta con ambas y por eso lo está teniendo. A sus 23 años se da el lujo de ilustrar portadas para una de las principales compañías de comics en Estados Unidos (DC), o en revistas como Mad.

$Y$ eso que no habla inglés.

- Estoy en eso. Pero mientras tanto hice un truco [...] (El Universal [Venezuela], 08/01/1997, CREA).

(30) $[\ldots]$ Y que al 'cura' o al suboficial se les salga un "p...tazo" puede inclusive ser explicable, tratándose del léxico de la guerra; pero que todo un burgomaestre -ni más ni menos que el Alcalde de Bogotá- haya dicho lo siguiente: -"En este país, de pronto hay muchos hijueputas, pero no son hijos de puta, sino de gente llamada de bien", a propósito de la propuesta del Defensor del Pueblo en el sentido de ligarles las trompas de Falopio a las trabajadoras sexuales para que no tengan hijos, sí implica que la naturaleza de las palabras está perdiendo su valor. Ya se había advertido aquí recientemente: o las palabras ya no significan lo que significan, o les perdimos el miedo a éstas y estamos, por ello, todos, en un grado de violencia verbal que azuza, sin duda, la violencia física que padecemos.

$Y$ eso que estoy de acuerdo con el Alcalde cuando dice, sin reatos, que no necesariamente los 'hijuep..tas' son los hijos de las prostitutas, sino que hay muchísimos de aquéllos entre los hijos de gente llamada de bien" (El Tiempo [Colombia], 06/09/1996, CREA).

Todos ellos introducen una nueva estructura proposicional tras una doble marca de puntuación fuerte: un punto, en lugar de una coma, y un cambio de párrafo. Y en todos ellos el valor concesivo parece diluirse a favor de un valor o bien digresivo o bien de adición de comentario, en cierto modo similar al valor que Martín Zorraquino y Portolés (1999: 4118) atribuyen a ahora bien como introductor de un miembro discursivo que elimina alguna conclusión que se pudiera inferir del miembro anterior:

(31) Dicen que toda opinión es respetable. En absoluto. Lo respetable es que todo el mundo se exprese. Ahora bien, una vez que han opinado, no tengo por qué respetarlos. Sólo faltaba (El País, 23/06/1996, ápud Martín Zorraquino y Portolés 1999: 4118).

La diferencia entre ahora bien e y eso que como marcadores que contribuyen a la progresión temática del discurso mediante el desarrollo de la información a través de la adición de un comentario (recuérdese que la $N G L E$ decía de y eso que que, en enunciados independientes, introduce apostillas a lo dicho previamente) estriba en la manera en que ordenan las proposiciones $\mathrm{P}$ (estado de cosas que apunta hacia una determinada conclu- 
sión) y Q (conclusión no hecha efectiva). Mientras que cuando se emplea ahora bien $\mathrm{P}$ precede a - Q, el uso de y eso que invierte el orden y enuncia en primer lugar - Q y, en segundo lugar, P. Si volvemos la mirada al esquema semántico en el que opera y eso que, que ya propusimos en la fig. número 2 supra, y lo contrastamos con el esquema semántico propio de ahora bien, que presentamos, a continuación, en la figura 4, la diferencia se ve mejor:

\begin{tabular}{|l|l|l|}
\hline P apunta a la conclusión Q & Ahora bien & - Q \\
\hline $\begin{array}{l}\text { Lo respetable es que todo el mundo } \\
\text { se exprese }\end{array}$ & Ahora bien & $\begin{array}{l}\text { una vez que han opinado, no tengo } \\
\text { por qué respetarlos }\end{array}$ \\
\hline
\end{tabular}

Figura 4. Esquema semántico de la construcción P. Ahora bien Q

\begin{tabular}{|l|l|l|l|}
\hline (causa elíptica) $=>$ & $\begin{array}{l}\text {-Q } \\
\text { efecto inesperado } \\
\text { desproporcionado) }\end{array}$ & $\begin{array}{l}\text { (P) circunstancia supuestamente } \\
\text { atenuadora del efecto (- Q) } \\
\text { propiciadora de Q }\end{array}$ \\
\hline & Se puso furioso & y eso que & se lo dije de buen modo \\
\hline & $\begin{array}{l}\text { A sus 23 años se da el lujo de } \\
\text { Estados Unidos para [... }\end{array}$ & Yeso que & no habla inglés \\
\hline
\end{tabular}

Figura 2'. Esquema semántico de la construcción -Q y eso que $\mathrm{P}$

En todos los ejemplos aducidos en que y eso que encabeza un nuevo párrafo, su función no parece estar asociada, en absoluto, con la vinculación, a la que nos referimos anteriormente, entre concesividad y argumentación o entre concesividad y negociación entre dos posturas opuestas, sino, más bien, con la esfera de la estructuración informativa, ya que lo que se lleva a cabo, en ellos, es la introducción de un nuevo tema, cuya distancia con respecto al anterior se materializa, gráficamente, en el cambio de párrafo. Lo interesante en este funcionamiento discursivo de y eso que como ordenador del discurso y, por tanto, como marcador de la estructuración informativa de los textos en que se emplea (un y eso que que no admite la paráfrasis con aunque o a pesar de que; cf. los ejemplos 32 a 35, lo que obliga a tachar otro de los rasgos semánticos enunciados en la fig. 1) es que, como vemos, en todos los ejemplos considerados la estructura semántica de la concesividad permanece inmutable. 
(32) El equipo de José Manuel Seco había sumado los seis últimos puntos de la primera vuelta, tras derrotar al Hernani en casa y el UPV fuera, pero no pudo enlazar su tercer éxito consecutivo en el inicio de la segunda.

\#Aunquela pesar de que no tardó en encarrilar el partido con un tanto madrugador de Txtxu, que aprovechó el penalti cometido sobre Txelis (El Diario Vasco, 11/01/2011, CREA).

(33) Jorge Valdano se atribuyó en exclusiva el error. "Quité a Dubovsky para evitar males mayores. Fue una decisión mía. El error es atribuible a la ansiedad atacante y a la novedad de la presencia de Redondo. Yo cuento en términos futbolísticos y no me fijé en las trabas burocráticas. El incidente tampoco ha sido determinante en el empate. Fue una anécdota, aunque grave".

\#Aunquela pesar de que todo había comenzado de cara para los de casa [...] (La Vanguardia, 24/10/1994, CREA).

(34) Hermann Mejía ha tenido la fortuna de unir dos cosas: talento y suerte. Una sola de ellas, como se sabe, no garantiza el éxito. Pero él cuenta con ambas y por eso lo está teniendo. A sus 23 años se da el lujo de ilustrar portadas para una de las principales compañías de comics en Estados Unidos (DC), o en revistas como Mad.

\#Aunquela pesar de que no habla inglés.

- Estoy en eso. Pero mientras tanto hice un truco [...] (El Universal [Venezuela], 08/01/1997, CREA).

(35) $[\ldots]$ Y que al 'cura' o al suboficial se les salga un "p...tazo" puede inclusive ser explicable, tratándose del léxico de la guerra; pero que todo un burgomaestre -ni más ni menos que el Alcalde de Bogotá- haya dicho lo siguiente: -"En este país, de pronto hay muchos hijueputas, pero no son hijos de puta, sino de gente llamada de bien", a propósito de la propuesta del Defensor del Pueblo en el sentido de ligarles las trompas de Falopio a las trabajadoras sexuales para que no tengan hijos, sí implica que la naturaleza de las palabras está perdiendo su valor. Ya se había advertido aquí recientemente: o las palabras ya no significan lo que significan, o les perdimos el miedo a éstas y estamos, por ello, todos, en un grado de violencia verbal que azuza, sin duda, la violencia física que padecemos. \#Aunquela pesar de que estoy de acuerdo con el Alcalde cuando dice, sin reatos, que no necesariamente los 'hijuep..tas' son los hijos de las prostitutas, sino que hay muchísimos de aquéllos entre los ijos de gente llamada de bien" (El Tiempo [Colombia], 06/09/1996, CREA)

En todos estos ejemplos, el rechazo de la sustitución de y eso que por aunque o a pesar de que parece debido a la ausencia, en aunque y en a pesar de que, del valor anafórico, imprescindible para el funcionamiento del esquema concesivo en el plano de la estructuración informativa y la progresión temática, que en y eso que manifiesta eso. Con todo, en estos contextos, el valor concesivo no se anula. Más bien al contrario, lo que se hace es explotar el esquema 'efecto inesperado + obstáculo inoperante' más allá de las fronteras de la oración, en el ámbito de la conexión no entre cláusulas, sino entre enunciados ${ }^{13}$. De

13 Por este motivo (cf. también infra el apartado de conclusiones), no parece especialmente acertado considerar estos ejemplos como cláusulas "independientes", tal como estipula el rasgo (e ii) de la fig. 1. Mejor que hablar de independencia resulta referirse, tal como se propone en la fig. 1" infra, a inicio de intervención/turno o de párrafo. 
hecho, no menos interesante que el mantenimiento del esquema semántico de la concesividad es el hecho de que también se preserve la naturaleza temática de la información expresada por la cláusula concesiva.

Tal como señala Pérez Saldanya (2014), las expresiones argumentativas de carácter concesivo suelen ocupar la posición inicial de los enunciados en que comparecen, una posición que la perspectiva interactiva o conversacionalista de los mecanismos concesivos defendida por autores como Couper-Kuhlen y Thompson (2000) se considera prototípica para la concesividad, debido al carácter temático de las cláusulas concesivas que remiten, a menudo de manera anafórica, a un cotexto anterior:

\begin{abstract}
Así, el elemento focalizado aparece prototípicamente en posición inicial de la construcción $\mathrm{y}$, en una consideración dialógica del dispositivo enunciativo, remite a una representación semántica previa, que puede ser meramente evocada o bien corresponder a una intervención de otro de los participantes en la interacción discursiva. [...] Desde esta perspectiva se puede explicar la prótasis de dichas construcciones como una asunción provisional y parcial de una hipótesis previa que puede estar expresada o latente en el cotexto o en el contexto extralingüístico. Tal hipótesis es recogida en el primer miembro de la construcción, como concesión a un punto de vista que es presentado o evocado pero que está destinado a ser contradicho por la antítesis explicitada en la apódosis (Pérez Saldanya 2014: 3702-3703).
\end{abstract}

Pues bien, esto es algo que en absoluto se pierde en el empleo de y eso que como marcador de estructuración de la información. Así, en textos de carácter narrativo como los que presentan los ejemplos que proceden de crónicas deportivas ( 27 y 28), el esquema semántico propio de y eso que se aprovecha para acentuar el contraste entre el desenlace del partido de fútbol que se relata y los hechos anteriores a dicho desenlace, que ya son conocidos por el lector; y, en ambos casos, dado que la publicación de la crónica es posterior a la difusión del resultado del partido por los medios audiovisuales, lo que se presenta tras y eso que es, necesariamente, información consabida. En textos descriptivos, como 29, se acentúa el contraste entre una carencia formativa (no hablar inglés), que debería haber impedido el triunfo en Estados Unidos de la persona sobre la que se habla, y el hecho sorprendente de que, aun así, haya conseguido tener éxito en este país. En este caso, la información consabida que expresa el enunciado introducido por y eso que es la de que para triunfar en un país anglosajón se debe dominar la lengua autóctona. En el último de los ejemplos que he traído a colación, el 30, nos encontramos ante una concesivo-informativa de la enunciación, donde se expresa un contraste entre el hecho de estar de acuerdo con el alcalde de Bogotá en determinadas cosas y la circunstancia de que esto no sea óbice para la crítica que se vierte contra él. Aquí lo que se da por consabido es la creencia de que las personas que normalmente están de acuerdo en determinadas cuestiones suelen estarlo también en otras

En vista de estas consideraciones, nos vemos obligados, una vez más, a revisar la información contenida en la fig. 1, que, una vez reformuladas las propiedades (d), (e ii) y (h), en una refacción que se suma a la ya realizada del rasgo $(\mathrm{g})$, quedará, finalmente -al menos por ahora-, tal como sigue: 
Caracterización morfosintáctica:

(a) NATURALEZA: Se asimila a las locuciones conjuntivas.

(b) RECCIÓN: Va seguida de indicativo.

Caracterización semántica:

(c) Fórmula enfática.

(d) Y ESO QUE: Debido a su contenido, salvo cuando funciona como ordenador de la información, admite paráfrasis con prótasis concesivas factuales introducidas por aunque o a pesar de que.

(e) PROPOSICIÓN INTRODUCIDA POR y eso que:

i. (en construcción dependiente): causa que ha sido ineficaz al operar en sentido contrario a lo enunciado en la primera oración.

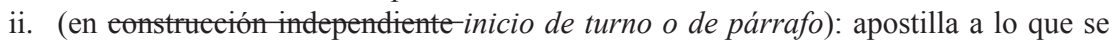
acaba de decir / estructura de cambio de tópico

(f) MODO VERBAL DE LA PROPOSICIÓN INTRODUCIDA POR y eso que: el indicativo que sigue a la locución marca el carácter factual del primer miembro.

Caracterización discursiva:

(g) Posición mayoritariamente pospuesta, con posibilidad tanto de anteposición como de interposición.

(h) Facilidad para apareer en una eonstrueción independiente-iniciar una nueva intervención o un nuevo párrafo.

(i) No se suele trar en los registros más formales.

Figura 1"”. Rasgos morfosintáticos, semánticos y discursivos de y eso que según la $N G L E$

Normalmente, la información temática no suele asociarse con estructuras que, como ocurre con la proposición encabezada por y eso que, se pospongan, por lo general, a otras proposiciones con las que estén íntimamente relacionadas. Ahora bien, si tanto la anteposición como la interposición son también posibles, incluso aunque la posposición no esté normalmente asociada a la expresión de información consabida, tendremos que aceptar que, en este caso, lo que contribuye a la interpretación del contenido de la cláusula encabezada por y eso que como información temática es todo el patrón morfosintático, semántico y discursivo de esta estructura en su conjunto: la rección de un verbo en indicativo, el valor escalar focal, propio de los esquemas concesivos, que también presenta y eso que, el valor semántico de obstáculo inoperante de los hechos que introduce... Todo ello, de manera solidaria, y en lo que parece conformar un esquema bipolar similar al estipulado por Narbona (1989, 1990 [2014]) para otras conjunciones y locuciones conjuntivas, coadyuva en la expresión de este valor concesivo enfático peculiar de y eso que, que recientemente se ha atrevido a asomar la cabeza más allá de las estrechas fronteras del enunciado biclausal, para descubrir las posibilidades de la conexión textual transoracional.

\section{CONCLUSIONES}

La estructura y eso que funciona, en el español actual, tanto como suma de los elementos $y+$ eso + que en enunciados en los que la concatenación de estas tres unidades no genera 
valores concesivos ${ }^{14}$, como como estructura gramaticalizada con valor concesivo. En este segundo caso, a veces actúa como locución conjuntiva y funciona como nexo entre dos cláusulas de un único enunciado, y otras veces desempeña el papel de un marcador del discurso que encabeza, tras punto y aparte, un nuevo párrafo. Tanto en un caso como en el otro, y debido a la característica co-construcción discursiva que impera en la oralidad de naturaleza dialógica, si nos encontramos en interacciones conversacionales, es posible que o bien la segunda cláusula o bien el segundo enunciado sean emitidos por un locutor distinto al que haya exteriorizado el primer miembro (cláusula o enunciado). Sin embargo, este tipo de estructuras, en las que y eso que abre intervención y turno, ni son las más frecuentes en la lengua actual, ni parecen estar en el origen de la gramaticalización de $y$ eso que con valor concesivo.

Por lo que respecta a la subida al nivel de la conexión textual de la locución conjuntiva, su aparición, sobre todo en el lenguaje periodístico, a principio de párrafo, como elemento de ordenación del discurso coadyuvante en la progresión informativa, y que excluye el uso de aunque o de a pesar de que como introductores de la cláusula concesiva (por su falta de valor anafórico), no ha traído consigo una desemantización del valor concesivo de la estructura, que mantiene, en su funcionamiento como marcador, el mismo esquema semántico que en su funcionamiento como conjunción. En ambos casos coinciden, también, características como la rección de modo indicativo para el verbo que sucede a y eso que, la posposición prácticamente sistemática de la construcción con y eso que a la proposición - $\mathrm{o}$ al enunciado- que expresa un efecto inesperado que lo formulado por la construcción de y eso que habría debido mitigar y la oportunidad de su utilización en registros tanto formales como informales.

Ahora bien, pese a lo afirmado por la $N G L E$ en relación con la facilidad que las construcciones que contienen y eso que manifiestan para aparecer en construcciones independientes, una facilidad que vendría avalada por el hecho de que se escriben, con frecuencia, tras un punto -que hasta hace poco siempre había sido y seguido, pero que hoy en día empieza a ser también y aparte-, el valor escalar que parece estar presente en el conector y eso que, unido al hecho de que su interpretación semántica requiere, necesariamente, la co-aparición de las proposiciones - Q y P, hacen que sea preferible rehuir de su consideración como posible construcción independiente en favor de su comprensión como parte de una estructura bipolar, tanto si esta es oracional como si es interoracional, similar a las propuestas por A. Narbona para dar cuenta de las antiguamente denominadas adverbiales impropias. Ello estaría en consonancia con las descripciones que M. Moliner y L. Santos Río proporcionan a propósito de y eso que. La primera parece avalar la interpretación de la construcción en la que participa y eso que como un esquema de bipolaridad en la medida en que el valor que asigna a este conector es de acentuación de la incongruencia entre las dos oraciones que enlaza, así como en relación con el hecho de que el carácter enfático que también la $N G L E$ reconoce en esta estructura no se asocia, por parte de Moliner, ni a la locución conjuntiva, ni a la proposición introducida por ella, sino que, acertadamente, se destaca, más bien, en relación con la proposición que antecede a la clásula o enunciado encabezados por y eso que:

14 Cf. supra, n. 10. 
Expresión concesiva, semejante a «aunque», pero que acentúa la incongruencia entre las dos oraciones enlazadas. [...] A veces, significa que cierto efecto expresado por la oración principal es muy grande, a pesar de la atenuación que supone lo expresado por la afectada por «y eso que»: 'Casi se desmayó, y eso que no le dijimos toda la verdad' (Moliner 2000, s.v. ese $e^{2}$; la cursiva es mía).

Como se señaló páginas atrás, el alcance del enunciado o de la cláusula encabezados por y eso que sobre el primer miembro del esquema concesivo ha sido también puesto de relieve por Luis Santos Río, en los siguientes términos:

Es muy típico su empleo cuando, queriendo el hablante encarecer el hecho narrado por su interlocutor, agrega como comentario la secuencia $Y$ eso que o bien dando a entender que, de no ser por el hecho que se narra, el que acaba de aducir el interlocutor sería todavía más intenso o bien añadiendo un aserto modalizado y enfático, presentado en proposición causa-explicativa condicionada, en el que se explicita ese detalle (-;Qué mal papel hizo en la carrera! -Y eso que le ayudaron, que, si no, ni siquiera llega a la meta; podría incluso suspenderse la frase tras el sintagma condicional: Y eso que le ayudaron, que si no...)" (Santos Río 2003, s.v. y eso que; la cursiva es mía).

Esta voluntad de encarecer lo expresado por el primer miembro, independientemente de que lo haya producido un interlocutor distinto o de que lo formule la misma voz que enuncia el miembro introducido por y eso que en el esquema concesivo pervive también, de momento, en el uso transfrástico de y eso que como marcador de apertura de párrafo. En el futuro será interesante comprobar si llegan a emerger ejemplos en los que y eso que pierda el valor que hemos ido describiendo a lo largo de estas páginas y en los que se convierta en un digresor puro, incapaz de establecer las relaciones de contraste y de promover los efectos de énfasis que comparten todos los ejemplos en que funciona como marcador de cambio de tópico.

\section{Referencias bibliográficas}

Bosque, I. y V. Demonte (dirs.) (1999). Gramática descriptiva de la lengua española. Madrid: Espasa. Briz, A. et al. (2002). Corpus de conversaciones coloquiales. Madrid: Arco/Libros.

Briz, A. y grupo Val.Es.Co. (2003). "Un sistema de unidades para el estudio del lenguaje coloquial", Oralia, 6, 7-61.

Briz, A. y grupo Val.Es.Co. (2014). "Las unidades del discurso oral. La propuesta Val.Es.Co. de segmentación de la conversación", Estudios de Lingüística del Español, 35, 13-73. En línea <http:// roderic.uv.es/handle/10550/43945> (Consulta: 09/01/2018)

Caballero, R. (1942). Diccionario de modismos de la lengua castellana. Madrid: Librería El Ateneo.

Cabedo, A. y S. Pons (en línea), Corpus Val.Es.Co. 2.0. http://www.valesco.es

Cortés Parazuelos, M. E. (2002). La expresión de la concesividad en español. Madrid: Universidad Complutense de Madrid. Tesis doctoral. En línea <http://eprints.ucm.es/4314/1/AH3017401.pdf > (Consulta: 09/01/2018)

Couper-Kuhlen, E. y S. Thompson (2000). "Concessive patterns in conversation". En E. CouperKuhlen y B. Kortmann (eds.), Cause, concession, contrast. Cognitive and discourse perspectives. Berlín: Walter de Gruyter, 381-410.

Flamenco García, L. (1999). "Las construcciones concesivas y adversativas". En Bosque, I. y V. Demonte (dirs.). Gramática descriptiva de la lengua española. Madrid: Espasa, vol. 3, pp. 3805-3878. 
Garachana Camarero, M. (1999). "Valores discursivos de las oraciones concesivas", Lingüística Española Actual, 2 (XXI), 189-205.

Koch, P. y W. Oesterreicher (1990). Gesprochene Sprache in der Romania: Französisch, Italienisch, Spanisch. Tübingen: Gunter Narr.

Koch, P. y W. Oesterreicher $\left(2007^{2}\right)$. Lengua hablada en la Romania: español, francés, italiano. Madrid: Gredos. Versión española de A. López Serena.

Koch, P. y W. Oesterreicher $\left(2011^{3}\right)$. Gesprochene Sprache in der Romania: Französisch, Italienisch, Spanisch. Berlín: De Gruyter.

López Serena, A. (2002). "Reseña de Koch, Peter/Oesterreicher, Wulf (1990), Gesprochene Sprache in der Romania: Französisch, Italienisch, Spanisch“, Lexis, 26 (1), 255-271.

López Serena, A. (2006). "La impronta estructuralista de las escuelas de Tubinga y Friburgo. Presente, pasado y futuro de la lingüística de las variedades alemana". En A. Roldán Pérez et al. (eds.). Caminos Actuales de la Historiografía Lingüistica. Actas del V Congreso Internacional de la Sociedad Española de Historiografía Lingüistica. Murcia: Universidad, 995-1007.

López Serena, A. (2013). "Variación y variedades lingüísticas: un modelo teórico dinámico para abordar el estatus de los fenómenos de variación del español hablado en Andalucía". En A. Narbona Jiménez (coord.). Conciencia y valoración del habla andaluza. Sevilla: Servicio de Publicaciones de la Universidad Internacional de Andalucía, 73-127.

López Serena, A. (2016). "De la gramática al discurso. En torno a la gramaticalización de y eso que en español moderno". Comunicación presentada en el Congreso Internacional Enunciado y Discurso: Estructura y Relaciones, celebrado en la Facultad de Filología de la Universidad de Sevilla los días 28 a 30 de noviembre de 2016 .

Martín Zorraquino, M. a A. y J. Portolés Lázaro (1999). "Los marcadores del discurso”. En Bosque, I. y V. Demonte (dirs.). Gramática descriptiva de la lengua española. Madrid: Espasa, vol. 3, pp. 4051-4213.

Moliner, M. (2000), Diccionario de uso del español. Madrid: Gredos (ed. abreviada).

Narbona Jiménez, A. (1989). Las subordinadas adverbiales impropias en español. I. Bases para su estudio. Málaga: Ágora.

Narbona Jiménez, A. (1990). Las subordinadas adverbiales impropias en español. II. Causales y finales, comparativas y consecutivas, condicionales y concesivas. Málaga: Ágora.

Narbona Jiménez, A. (2014). Las subordinadas adverbiales impropias en español. Edición de A. López Serena. Sevilla: Athenaica, 2 vols.

Pérez-Rioja, J. A. $\left(1966^{6}\right)$. Gramática de la lengua española. Madrid: Tecnos.

Pérez Saldanya, M. (2014). "Oraciones concesivas", en C. Company (dir.), Sintaxis histórica de la lengua española. Tercera parte: Adverbios, preposiciones y conjunciones. Relaciones interoracionales. México: UNAM, 3697-3839.

Real Academia Española: Banco de datos (CORDE) [en línea]. Corpus diacrónico del español. $<\mathrm{http}: / /$ www.rae.es $>$.

Real Academia Española: Banco de datos (CREA) [en línea]. Corpus de referencia del español actual. $<$ http://www.rae.es>.

Real Academia Española y Asociación de Academias de la Lengua Española (2009). Nueva gramática de la lengua española. Madrid: Espasa.

Santos Río, L. (2003). Diccionario de partículas. Salamanca: Luso-Española de Ediciones.

Seco, R. (1985[1930]). Manual de gramática española. Madrid: Aguilar, 10ª ed. Revisada por M. Seco. 
